\title{
En tiempo de pandemia y de quedarse en casa Ande promueve procesos de mediación pedagógica y acciones en beneficio de la población estudiantil y su afiliación.
}

\author{
Gilberto Cascante Montero. ${ }^{(1)}$ \\ ${ }^{(1)}$ Presidente de la Asociación Nacional de Educadores y Educadores de Costa Rica, email: \\ gilbertohospi@hotmail.com
}

Contacto: gilbertohospi@hotmail.com

Recibido: 05-05-2020

Aprobado: 08-06-2020

\section{Resumen}

El 17 de marzo, el Ministerio de Educación Pública de Costa Rica (MEP), tomó la decisión de suspender el curso lectivo, debido a la pandemia provocada por el COVID-19. Desde ese momento, ANDE (Asociación Nacional de Educadores y Educadoras de Costa Rica), ha promovido diferentes campañas en beneficio de toda la población estudiantil, sus familias y el personal docente:

"La Educación continúa en casa". Esta campaña visibiliza la importante labor del personal docente, para continuar con los procesos de enseñanzaaprendizaje fuera de las aulas.

Mediante la publicación en nuestros medios virtuales, docentes de todo el país, exponen diferentes experiencias pedagógicas, para primaria y secundaria, las cuales comparten con estudiantes, sus familias y colegas.

Asimismo, el trabajo docente virtual, prosigue con la asignación de trabajos, repasos, prácticas, nuevos contenidos, que hacen llegar a nuestra población estudiantil, por medios virtuales o los que consideren más convenientes y para los que ANDE ha facilitado estrategias de capacitación y herramientas tecnológicas, como apoyo a estos servicios educativos.

ANDE SE SUMA: (andesesuma.ande.cr). Se trata de un sitio web, en el cual las y los docentes, incluyen diversos materiales didácticos, que permiten al estudiantado, continuar con su proceso pedagógico y registrar su acceso.

Además, cuenta con capacitaciones virtuales para el sector educación, en temas de informática, pedagógicos, sindicales, laborales y un apartado especial relacionado con el COVID-19.
De esta forma, ANDE se une al valioso trabajo docente y a la formación de nuestra población estudiantil, mediante espacios totalmente gratuitos, con el objetivo de no interrumpir los procesos educativos, en esta difícil circunstancia para la sociedad costarricense.

\section{Otras acciones emprendidas por ANDE}

\section{Solución de distribución de alimentos en centros} educativos

ANDE, ante la problemática suscitada por la suspensión del curso lectivo, presentó al MEP, la alternativa de entregar paquetes de víveres, para beneficiar a las familias del alumnado, que acude a los comedores escolares.

Con esta medida, ANDE responsablemente promovió el acatamiento de las medidas sanitarias dictadas por el Ministerio de Salud, en aras de evitar el contagio, en el sector educativo.

ANDE ha considerado urgente y así lo ha hecho saber, la revisión y modificación de todas las directrices emitidas por el MEP, en cuanto a la permanencia de personal administrativo-docente y administrativo, en los centros educativos, debido a los riesgos que enfrentan.

\section{ANDE presentó nuevas medidas para resguardar} la salud

Para proteger la salud de las personas integrantes de la comunidad educativa, ANDE planteó a la Ministra de Educación Pública, las siguientes acciones, de acuerdo con las instrucciones del Ministerio de Salud.

1. Otorgar licencia con goce de salario, para todas las personas funcionarias del MEP, 
con factores de riesgo, que presenten un dictamen médico.

2. Permitir la justificación de ausencias, registradas en marzo, para el estudiantado con factores de riesgo, mediante la presentación de un dictamen médico.

ANDE insta a la comunidad educativa y poblacional, para estimular y propiciar en nuestra juventud y niñez, el respeto y el amor por las personas adultas mayores, mediante el cuidado y la protección.

En esta coyuntura social, las y los docentes, también podemos ejercer nuestra labor pedagógica en nuestras comunidades, al explicar sobre las repercusiones del COVID-19 en la salud y la importancia de cumplir con las medidas del Ministerio de Salud y del Gobierno.

ANDE convoca a toda nuestra afiliación a ejercer con responsabilidad el llamado que hoy Costa Rica demanda de nosotras/as y que nos brinda la noble profesión docente, como personas protagonistas en el significado transformador de las coyunturas sociales. 